\title{
A CLINICAL STUDY OF PROGNOSTIC FACTORS IN PERITONITIS SECONDARY TO HOLLOW VISCUS PERFORATION: IN A TERTIARY HOSPITAL
}

\author{
Bhanuprakash K. R1, Prashanthkumar B², Nagaraj Shankreppa ${ }^{3}$
}

${ }^{1}$ Assistant Professor, Department of General Surgery, Bangalore Medical College and Research Institute, Bangalore.

2 Post Graduate, Department of General Surgery, Bangalore Medical College and Research Institute, Bangalore.

${ }^{3}$ Post Graduate, Department of General Surgery, Bangalore Medical College and Research Institute, Bangalore.

\begin{abstract}
\section{BACKGROUND AND OBJECTIVES}

Typhoid ileal perforation is a common problem seen in tropical countries. Over the years, advances in the treatment of typhoid fever has decreased the incidence of typhoid ileal perforation. This study is conducted to throw a light on prognostic factor s in the surgical outcome of typhoid ileal perforations.
\end{abstract}

\section{METHODOLOGY}

Fifty consecutive patients clinically diagnosed as having typhoid ileal perforation was taken for the study over a period of 18 months from November 2011 to May 2013. Pre-operative patients were investigated for the air under the diaphragm using upright chest X-ray and erect abdomen X-rays. Blood culture and Widal tests were done to diagnose the patients that they were suffering from typhoid fever. Patients with general peritonitis due to other causes excluded from the study.

\section{RESULTS}

Out of 50 patients, there were $40(80 \%)$ males and $10(20 \%)$ females, thus the male:female ratio was 4:1. Their ages ranged from 16-58 years. There were 32 patients presented early and 18 patients presented lately. The patients presented to the hospital with spectrum of symptoms. All the patients had pain abdomen to present with, out of which 29 patients had fever, 33 had dehydration and 16 had shock on presentation. In these 50 patients, 33 patients had single perforations and 17 had multiple perforations. The single perforation was treated with simple closure and resection anastomosis was done in cases of multiple perforations. The patients were observed for complications of surgery. The mean hospital stay was 13.28 days. We lost 6 cases. There were 19 ca ses of wound infection, 12 cases of wound dehiscence, 7 cases of enterocutaneous fistula, 4 cases of respiratory tract infections. The blood culture was positive in 4 cases and the culture yielded Salmonella typhi. The Widal test was positive in 44 cases. There were 13 cases of abdominal fluid culture positive. All yielded the growth of E. coli.

\section{CONCLUSION}

Typhoid ileal perforation is one of the most common surgical emergency encountered by the general surgeon. Widal test is still useful in the diagnosis of typhoid fever in our country. The number of perforations and the peritoneal contamination and the delay in getting medical facility-surgery, shock at the time of presentation at hospital are directly proportional to the morbidity and mortality. Availing early medical facility, which is a modifiable risk factor. If timely early medical attention is sought, majority of morbidity and mortality can be tackled.

\section{KEYWORDS}

Typhoid, Ileal Perforation, Prognosis.

HOW TO CITE THIS ARTICLE: Bhanuprakash KR, Prashanthkumar B, Shankreppa N. A clinical study of prognostic factors in peritonitis secondary to hollow viscus perforation: in a tertiary hospital. J. Evolution Med. Dent. Sci. 2016;5(42):2585-2590, DOI: $10.14260 /$ jemds/2016/605

\section{INTRODUCTION}

Peritonitis due to hollow viscous perforation continues to be one of the most common surgical emergencies to be attended by a surgeon on call duty. This may be due to persistence of the various risk factors among the general population like $\mathrm{H}$. pylori infection, NSAID's, enteric fever and several others. This condition most of the times needs an emergency surgical intervention, a scoring system should be able to assess the need, type and quality of the care required for a particular patient.

Financial or Other, Competing Interest: None.

Submission 10-03-2016, Peer Review 20-04-2016,

Acceptance 26-04-2016, Published 25-05-2016.

Corresponding Author:

Dr. Nagaraj Shankreppa,

Room No. 217, BMC Men's PG Hostel,

Near Amanath Co-Op. Bank,

Shivajinagar,

Bangalore.

E-mail: nagarajdoc76@gmail.com

DOI: $10.14260 /$ jemds $/ 2016 / 605$
Realizing the need for a simple accurate scoring system in these conditions, the present study was undertaken to evaluate the performance of MPI scoring system in predicting the risk of morbidity and mortality in patients with peritonitis due to hollow viscous perforation.

Several scoring systems are in place to stratify the patients with peritonitis due to hollow viscous perforation like APS, SIS, APACHE and BOEYS. Utilization of scoring systems would be of great help in salvaging a priceless life of a patient. Our study is aimed at testing the effectiveness of Mannheim Peritonitis Index.

The management of peritonitis due to hollow viscus perforation poses diagnostic and therapeutic challenges to general surgeons practicing in resource limited countries. ${ }^{1,2}$ Surgery is considered the treatment of choice in order to improve the chances of survival of patients with this condition, who most often present late. ${ }^{3}$ The management of these patients provides a number of unique challenges to the attending surgeon. Many of these patients present at and are managed in rural hospitals, where resources are often very 
limited. Late presentation, inadequate preoperative resuscitation, delayed operation, number of perforations and the extent of faecal peritonitis have been found to have a significant effect on prognosis. ${ }^{4,5}$

While mortality in the developed world has dropped to between $0 \%$ and $2 \% .6,7$ Mortality in the developing world remains high at between $9 \%$ and $22 \% .8,2,9$ The reasons for this state of affairs have not been evaluated in our setting. The purpose of this study was to describe our experiences on the surgical management of peritonitis secondary to hollow viscus perforation outlining the clinical profile and treatment outcome of this disease and to determine the prognostic factors for morbidity and mortality in our local setting. It is hoped that identification of these factors will help in policy decision making, prioritizing management and improving the quality of care.

The purpose of operative protocol is to correct the pathology while avoiding any serious accidents and to adopt a surgical procedure, which is associated with minimal complications. ${ }^{10}$ Perforation of the small bowel is a common abdominal surgical emergency faced by the general surgeon. Perforation of the small bowel is relatively common in endemic areas of typhoid, tuberculosis and parasitic infestations. Perforated small bowel challenges the surgeon's skill and his knowledge of preoperative, intra-operative and post-operative care of severely ill surgical patient. In patients with sudden onset of abdominal pain without high index of suspicion and timely surgical intervention results in significant mortality and morbidity. Surgery plays an important role in the management of small bowel perforation. Evaluation and management of small intestinal perforation provide some of the most challenging experiences for a surgeon with advent of new technology. This study aims to study the factors affecting the outcome in peritonitis secondary to hollow viscus perforations.

\section{AIMS AND OBJECTIVES}

\section{The AIMS and Objectives of this Study are}

To study the difference in survival rates of early and late presentation in peritonitis due to hollow viscus perforation at the hospital. To study various prognostic factors in peritonitis due to hollow viscus perforations on the outcome of patient.

\section{Note}

Early presentation is taken as the presentation of the patient within 24 hours of appearance of pain abdomen. Late presentation is taken as the presentation of the patient after more than 24 hours of appearance of pain abdomen.

\section{MATERIALS AND METHODS}

\section{Source of Data}

It includes all cases who are above 16 years of age and undergoing surgery for peritonitis due to hollow viscus perforation under surgical units at Bowring and Lady Curzon Hospitals attached to Bangalore Medical College and Research Institute, Bengaluru.

\section{METHODS OF COLLECTION OF DATA Study Design}

Prospective Comparative Study.

\section{Study Period}

July 2014 to December 2015.

\section{Place of Study}

Bowring and Lady Curzon Hospitals attached to Bangalore Medical College and Research Institute, Bengaluru.

\section{Sample Size}

50 patients.

\section{Inclusion Criteria}

All patients above 16 years undergoing surgery for peritonitis due to hollow viscus perforation due to Acid peptic disease, Typhoid, Tuberculosis, Gangrenous cholecystitis, Appendicitis, Malignancy and given written consent to participate in this study.

\section{Exclusion Criteria}

Patients with hollow viscous perforation due to trauma, patients with any other significant illness which is likely to affect the outcome more than the disease in study and pregnant mothers and patients not willing to give consent for study.

\section{METHODOLOGY}

Fifty consecutive patients clinically diagnosed as having peritonitis due to hollow viscus perforation was taken for the study over a period of 18 months from July 2014 to December 2015. Pre-operative patients were investigated for the air under the diaphragm using upright chest X-ray and erect abdomen X-rays. Routine blood investigations and Widal tests were done. All patients were determined of their packed cell volume, serum electrolytes, urea and creatinine levels. ECGs were also taken. Diagnosis was further supported by intraoperative findings of gastric, duodenal or ileal perforation with associated peritoneal soilage. Patients with general peritonitis due to trauma and idiopathic intra-abdominal abscesses were excluded from the study. Pre-operative resuscitation was done including correcting anaemia, correcting electrolyte imbalances, adequate urine output was obtained and the patients were brought out of shock. Patients were kept nil by mouth.

Inj. tetanus toxoid $0.5 \mathrm{cc}$ was given intramuscularly. One gram of inj. Ceftriaxone given as prophylactic antibiotic. On all patients, general anaesthesia was used. Exploratory laparotomy was done with midline incision. Operative findings were noted including the amount of fluid, pus and fecal matter and peritoneal contamination. The gastric and duodenal perforations were closed with Graham's omental patch and the edges of the ileal perforations were freshened and primary closure was done transversely in two layers. Resection anastomosis was done in selected cases. Edge biopsy from the ulcer was sent for histopathological examination. Peritoneal cavity was irrigated with copious amount of normal saline. Drains were inserted to drain the paracolic gutter and pelvic cavity; these were connected to graduated plastic bags. Wound was closed with mass closure technique and the appropriate antibiotics were put. The majority of cases were treated with IV Ceftriaxone and Metronidazole for a period of ten days. Attention was given to wound infection, wound dehiscence, residual intra-abdominal abscess, faecal fistula and death.

\section{Statistical Methods Involved}

The data obtained tabulated and percentage calculated wherever necessary. The significance of difference in early and late presentation of perforation at the hospital, the peritoneal 
faecal contamination, presence or absence of shock at presentation, effect of the number of perforations on the outcome calculated.

\section{RESULTS}

Fifty patients of peritonitis due to hollow viscus perforation admitted between July 2014 and December 2015 were included in this study. Patients have been grouped into time of presentation in the hospital, i.e. early against late and number of perforations they are having, i.e. single against multiple. There were both males and females. Their ages ranged from 16 years to 70 years with a mean of 32.6 years. There were $40(80 \%)$ males and $10(20 \%)$ females, thus the male:female ratio was $4: 1$. Their ages ranged from $16-70$ years. All the patients presented to hospital with the history of pain abdomen. They were classified into early and late presenters. The patients presented to the hospital with a history of pain in abdomen of less than 24 hours were considered as early presenters and the others considered late presenters. Hence, 32 patients presented early and 18 patients presented lately.

The patients presented to the hospital with spectrum of symptoms. All the patients had pain abdomen to present with. Out of which 15 had fever, 33 had dehydration and 16 had shock on presentation. They were resuscitated to correct dehydration and electrolyte imbalance. Blood was sent to Widal along with other routine investigations. The abdominal taps were done in all the patients and the tapped fluid sent for culture and sensitivity. Erect X-ray of the abdomen and chest were taken to confirm hollow viscus perforation and patients were subjected for exploratory laparotomy. All the patients were given $1 \mathrm{gm}$ of Inj. Ceftriaxone at the time of induction of anaesthesia.

The gastric and duodenal perforations were closed with Graham's omental patch repair and the ileal perforations were repaired by means of simple two layer closure or resection anastomosis depending on the number and sites of perforations. The patients were observed for complications of surgery. The mean hospital stay was 13.28 days. We lost 6 cases. There were 9 cases of wound infection, 2 cases of wound dehiscence, 4 cases of respiratory tract infections. The blood culture was positive in 4 cases and the culture yielded Salmonella typhi.

\section{Sex and Age Incidence}

The age of patients ranged from 16 to 70 years. Perforation commonly occurred in the third and fourth decades of life with $66 \%$ of patients between the ages of 20 and 40 . The distributions of age and sex in all cases distributions are shown in Table 1.

\begin{tabular}{|c|c|c|c|c|}
\hline Age & Male & Female & Total & Percent \\
\hline $10-20$ & 3 & 3 & 6 & 12 \\
\hline $21-30$ & 11 & 7 & 18 & 36 \\
\hline $31-40$ & 15 & 0 & 15 & 30 \\
\hline $41-50$ & 8 & 0 & 8 & 16 \\
\hline $51-70$ & 3 & 0 & 3 & 6 \\
\hline Total & $\mathbf{4 0}$ & $\mathbf{1 0}$ & $\mathbf{5 0}$ & $\mathbf{1 0 0}$ \\
\hline \multicolumn{7}{|r}{}
\end{tabular}

Table 1: Age and Sex Incidence in Perforations

\section{Symptoms and Signs}

Most of the patients presented with symptoms and signs of peritonitis. The commonest symptoms were abdominal pain, fever and vomiting. The commonest signs were abdominal tenderness, guarding, intra-abdominal free fluid, distension and dehydration. Most patients of typhoid gave a history of fever; 32 percent of patients were in shock. Symptoms and signs are shown in Table 2 and Table 3.

\begin{tabular}{|c|c|c|}
\hline Symptom & Number & Percentage \\
\hline Abdominal pain & 50 & $100 \%$ \\
\hline Fever & 15 & $30 \%$ \\
\hline Vomiting & 13 & $26 \%$ \\
\hline Diarrhoea & 13 & $26 \%$ \\
\hline Constipation & 06 & $12 \%$ \\
\hline \multicolumn{2}{|c|}{ Table 2: Symptoms of Patients who } \\
Presented with Peritonitis \\
\hline
\end{tabular}

\begin{tabular}{|c|c|c|}
\hline Sign & Number & Percentage \\
\hline Dehydration & 33 & $66 \%$ \\
\hline Tenderness & 50 & $100 \%$ \\
\hline Guarding & 50 & $100 \%$ \\
\hline Distension of the abdomen & 50 & $100 \%$ \\
\hline Free fluid & 50 & $100 \%$ \\
\hline Shock & 16 & $32 \%$ \\
\hline \multicolumn{2}{|c|}{ Table 3: Signs of Peritonitis } \\
\hline
\end{tabular}

\section{INVESTIGATIONS}

X-Ray

Pneumoperitoneum in chest and erect abdominal x-ray was seen in $100 \%$ of patients.

\section{Haematology and Biochemistry}

Haemoglobin was less than $10 \mathrm{~g} / \mathrm{dL}$ in none of the patients and Albumin of less than $3.5 \mathrm{~g} / \mathrm{dL}$ was seen in 28 (56\%) of cases. Azotaemia as defined as Blood Urea of more than $52 \mathrm{mg} / \mathrm{dL}$ and/or Serum Creatinine more than $2 \mathrm{mg} / \mathrm{dL}$ was seen in $20 \%$ of patients.

\section{Microbiology}

Blood cultures were done in suspected patients and growth was obtained in 4 . Salmonella typhi was grown in all 4 patients. The typhoid growths were sensitive to cefotaxime, ceftriaxone, piperacillin and amikacin.

\section{Histopathology}

Pathological examination of either resected specimens or scrapings from the edge of the ulcer was done in gastric and ileal perforation of the patients. A report suggestive of typhoid was seen in 17 cases.

\section{Lag Period}

It is the time interval between the onset of abdominal pain and the presentation of the patient at the hospital. In our study, lag period was between 6 hours and 76 hours as shown in Table 4 .

\begin{tabular}{|c|c|c|}
\hline Lag Period in Hours & No. of Cases & Percentage \\
\hline$<24$ & 31 & 62 \\
\hline $25-48$ & 15 & 30 \\
\hline $49-72$ & 03 & 06 \\
\hline$>72$ & 01 & 02 \\
\hline Total & $\mathbf{5 0}$ & $\mathbf{1 0 0}$ \\
\hline \multicolumn{2}{|c}{ Table 4: Lag Period in Peritonitis } \\
\hline
\end{tabular}

\section{Surgical Procedures}

Graham's omental patch was done in cases of gastric and duodenal perforations (90\%). Simple primary 2-layer closure 
was done in 3 patients (6\%). Resection and anastomosis were done in 2 patients (4\%) Table 5.

\begin{tabular}{|c|c|c|}
\hline Procedure & $\begin{array}{c}\text { Number } \\
\text { of } \\
\text { Patients }\end{array}$ & Percentage \\
\hline $\begin{array}{c}\text { Graham's Omental Patch } \\
\text { Closure }\end{array}$ & 45 & $90 \%$ \\
\hline Simple Primary Closure & 3 & $6 \%$ \\
\hline Resection and Anastomosis & 2 & $4 \%$ \\
\hline Total & $\mathbf{5 0}$ & $\mathbf{1 0 0 \%}$ \\
\hline
\end{tabular}

Table 5: Surgical Procedures Done for Peritonitis

\section{Number and Site of Perforation}

Single perforations were observed in 48 (96\%) patients, two perforations were found in $1(2 \%)$ patient, three perforations in $1(2 \%)$ patients, in multiple perforation patients perforations occurred within $30 \mathrm{~cm}$ from the ileocecal junction Table 6.

\begin{tabular}{|c|c|c|}
\hline $\begin{array}{c}\text { No. of } \\
\text { Perforations }\end{array}$ & $\begin{array}{c}\text { No. of } \\
\text { Cases }\end{array}$ & Percentage \\
\hline 1 & 48 & $96 \%$ \\
\hline 2 & 01 & $2 \%$ \\
\hline 3 & 01 & $2 \%$ \\
\hline Total & $\mathbf{5 0}$ & $\mathbf{1 0 0} \%$ \\
\hline \multicolumn{2}{|c|}{ Table 6: No. of Perforations } \\
\hline
\end{tabular}

\section{Complications}

Complications occurred in 15 (30\%) of cases. The common complications seen were respiratory tract infections, wound infections, wound dehiscence. Out of 50 patients wound infections was seen in $9(18 \%)$ patients, would dehiscence in $2(4 \%)$ patients and respiratory complications in $4(8 \%)$ Table 7.

\begin{tabular}{|c|c|c|c|}
\hline Complication & $\begin{array}{c}\text { Simple } \\
\text { Closure }\end{array}$ & $\begin{array}{c}\text { Resection } \\
\text { Anastomosis }\end{array}$ & Total \\
\hline $\begin{array}{c}\text { Respiratory Tract } \\
\text { Infections }\end{array}$ & 02 & 02 & 04 \\
\hline $\begin{array}{c}\text { Wound } \\
\text { Infections }\end{array}$ & 05 & 04 & 09 \\
\hline $\begin{array}{c}\text { Wound } \\
\text { Dehiscence }\end{array}$ & 01 & 01 & 02 \\
\hline Table 7: Surgical Procedures and their Complications \\
\hline
\end{tabular}

\section{Operating Time and Hospital Stay}

The operating time varied from 60 minutes to 100 minutes for Graham's omental patch closure, an average being 75 mins.; and simple primary closure, an average being 88 minutes. In case of resection anastomosis the time span was 90 to 120 minutes, the average was 116 minutes. Resection and anastomosis took a longer time than simple closure. The length of hospital stay ranged from 6 days to 22 days; the average hospital stay being 13.28 days. The patients who underwent Graham's omental patch had average stay of 10 days and simple primary closure had an average stay of 12 days. Their counterparts who had the procedure of resection anastomosis had an average stay of 16 days. Table 8, Table 9 and Table 10.

\begin{tabular}{|c|c|c|c|c|c|}
\hline Procedure & $\begin{array}{c}60 \text { to } \\
80 \text { min }\end{array}$ & $\begin{array}{c}81 \text { to } \\
90 \mathrm{~min}\end{array}$ & $\begin{array}{c}91 \\
\text { to } 100 \\
\min \end{array}$ & $\begin{array}{c}101 \\
\text { to } 110 \\
\text { min }\end{array}$ & $\begin{array}{c}111 \\
\text { to } 120 \\
\text { min }\end{array}$ \\
\hline $\begin{array}{l}\text { Graham's } \\
\text { Omental } \\
\text { Patch }\end{array}$ & 40 & 05 & - & - & - \\
\hline $\begin{array}{l}\text { Simple } \\
\text { Primary } \\
\text { Closure }\end{array}$ & - & 03 & - & - & - \\
\hline $\begin{array}{c}\text { Resection } \\
\text { Anastomosis }\end{array}$ & - & - & - & 02 & - \\
\hline Total & 40 & 8 & - & 02 & - \\
\hline \multicolumn{6}{|c|}{ 8: Duration of Surgical Procedures } \\
\hline
\end{tabular}

\begin{tabular}{|c|c|}
\hline Procedure & Mean Time of Surgery \\
\hline $\begin{array}{c}\text { Graham's Omental Patch } \\
\text { Closure }\end{array}$ & 75 minutes \\
\hline Simple Primary Closure & 88 minutes \\
\hline Resection Anastomosis & 116 minutes \\
\hline Average Time Per Patient & 102 minutes \\
\hline \multicolumn{2}{|c|}{ Table 9: Average Time of Surgery } \\
\hline
\end{tabular}

\begin{tabular}{|c|c|c|c|}
\hline $\begin{array}{c}\text { Days in } \\
\text { Hospital }\end{array}$ & $\begin{array}{c}\text { Graham's } \\
\text { Omental } \\
\text { Patch }\end{array}$ & $\begin{array}{c}\text { Simple } \\
\text { Primary } \\
\text { Closure }\end{array}$ & $\begin{array}{c}\text { Resection } \\
\text { Anastomosis }\end{array}$ \\
\hline $\begin{array}{c}7 \text { to } 14 \\
\text { Days }\end{array}$ & 40 & 03 & 00 \\
\hline $\begin{array}{c}15 \text { to } 21 \\
\text { Days }\end{array}$ & 05 & 00 & 02 \\
\hline >22 Days & 00 & 00 & 00 \\
\hline $\begin{array}{c}\text { Average } \\
\text { Hospital } \\
\text { Stay }\end{array}$ & $\mathbf{1 0}$ & $\mathbf{1 2 . 0}$ & $\mathbf{1 6}$ \\
\hline \multicolumn{4}{|c}{ Table 10: Duration of Hospital Stay } \\
\hline
\end{tabular}

\section{Mortality}

Among the 50 patients, 4 patients succumbed to death. The mortality rate was $8 \%$. Septicaemia and acute respiratory distress syndrome were the causes of death. Table 11.

\begin{tabular}{|c|c|c|}
\hline Cause of Death & Number & Percentage \\
\hline Septicemia & 03 & $75 \%$ \\
\hline $\begin{array}{c}\text { Acute respiratory } \\
\text { distress } \\
\text { syndrome }\end{array}$ & 01 & $25 \%$ \\
\hline Total & 04 & $100 \%$ \\
\hline
\end{tabular}

\section{Prognostic Factors}

A variety of factors influence in the outcome of peritonitis due to hollow viscus perforation. This study aimed at the influence of the number of perforations and the time duration of presentation of the patient at the hospital after the onset of pain abdomen on the outcome. In this study, out of 50 patients 32 presented to the hospital within 24 hours of onset of pain. Among these 32 patients, all had single perforations and were treated with Graham's omental patch or simple primary closure. Only 4 patients developed complications. There were no deaths in this arm; 18 patients presented to the hospital 24 hours after the onset of pain abdomen. In this arm, 16 patients had single perforation and received Graham's omental 
patch/simple primary closure, 2 had multiple perforations and subjected to resection-anastomosis. There were 11 complications in this category. All the death occurred in this group.

\section{Lag Period}

The time interval between the onset of pain and the presentation of the patient at the hospital has great impact on the outcome. The complications and death were more in those patients who presented to the hospital after 24 hours. Table 12.

\begin{tabular}{|c|c|c|c|c|c|c|}
\hline \multirow[b]{2}{*}{$\begin{array}{l}\text { Lag Period } \\
\text { Duration } \\
\text { in Hours }\end{array}$} & \multicolumn{3}{|c|}{$\begin{array}{c}\text { Graham's Omental } \\
\text { Patch/Simple Primary } \\
\text { Closure }\end{array}$} & \multicolumn{3}{|c|}{$\begin{array}{c}\text { Resection } \\
\text { Anastomosis }\end{array}$} \\
\hline & 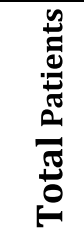 & 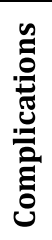 & 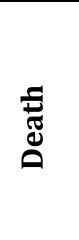 & 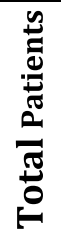 & 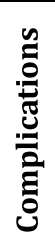 & 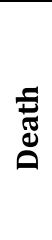 \\
\hline$<24$ & 32 & 04 & 00 & 00 & 00 & 00 \\
\hline$>24$ & 16 & 09 & 03 & 02 & 02 & 01 \\
\hline
\end{tabular}

\begin{tabular}{|c|c|c|c|}
\hline $\begin{array}{c}\text { Lag Period in } \\
\text { Hours }\end{array}$ & $\begin{array}{c}\text { No. of } \\
\text { Patients }\end{array}$ & $\begin{array}{c}\text { No. of } \\
\text { Deaths }\end{array}$ & Percentage \\
\hline$<24$ & 32 & 00 & $00 \%$ \\
\hline$>24$ & 18 & 04 & $22.22 \%$ \\
\hline \multicolumn{3}{|c|}{$\begin{array}{c}\text { Table 13: Relation of Lag Period to } \\
\text { Mortality and Complications }\end{array}$} \\
\hline
\end{tabular}

\section{DISCUSSION}

Primarily, the mortality and the morbidity rate depend on the general status of the patient and the duration of disease evolution before surgical treatment. That is why it is so important to provide adequate preoperative management associating aggressive resuscitation with antibiotic therapy. $3,11,12$ This study has been undertaken in order to contribute to the improvement in the knowledge of prognostic factors of this disease. Peritonitis due to hollow viscus perforation has preponderance among males seen in our study with male-to-female ratio of $4: 1$, similar to other's studies.3,13,14 Most of the patients in our study belonged to 2140 years, which is also same as other studies, while Aziz. ${ }^{14}$ and Ajao reported second and third decades of life in their studies.

All the patients presented to the hospital with history of pain abdomen and abdominal distension. Other major complaints involved are fever, vomiting, diarrhoea and constipation. Most patients presented with features suggestive of peritonitis. Examination revealed tenderness, guarding, distension and intraperitoneal free fluid; 16 patients were in shock on admission. Examination revealed signs of toxaemia and acute abdomen. All patients belonged to low socioeconomic class. Although, many factors affect the prognosis of but the most important are the number of perforations and the time interval between perforation and surgery.

The need for adequate resuscitation resulted in further delay before operation in some of our patients who had presented in a poor state, which was also found to affect the outcome adversely.

Single perforation was associated with less complications. Multiple perforations were associated with more severe complications like wound dehiscence and increased mortality treated with resection anastomosis. In our study, septicaemia was found in $4(8 \%)$ patients. Overwhelming septicaemia was the major cause of mortality in this study. Overall mortality rate was $12 \%$, which is less comparable to other studies as $28 \%$ reported by Adesunkanmi and Ajao. ${ }^{12,13} 16.4 \%$ by Talwar. ${ }^{3}$ and $13.8 \%$ by Aziz. ${ }^{14}$ and $48 \%$ by Ameh. Most patients died in the second post-operative period and survival beyond the $14^{\text {th }}$ post-operative day was associated with a high chance of complete recovery.

Survivors of perforation were faced with various postoperative complications, such as wound infection and wound dehiscence with prolonged hospitalization and increased cost of management. The overall wound infection was observed in $18 \%$. In the literature wound infection had been observed 33-100\%.4,5 Mechanical causes and malignancy are the commonest causes of small bowel perforation in the western world. Mechanical causes and lymphomas accounted for $40.7 \%$ of perforations in the series by Dixon. ${ }^{15}$ Malignancy was the commonest cause in the series by Orringer. ${ }^{16}$ There was a male preponderance with the male:female ratio in this study being 4:1. Chest X-ray is a useful investigation to detect hollow viscus perforation. Free gas was seen under the diaphragm in almost all of perforations. Abdominal X-ray revealed gas features suggestive of ileus. Pneumoperitoneum has been reported in $52 \%$ to $82 \%$ in studies by Hadley, Archampong, Tacyildiz and Vaidyanathan. ${ }^{17,18,19,20}$

The common complications were wound infection, wound dehiscence and respiratory complication which was compared with published reports. 17,21,22,23 Faecal fistula was seen in only one patient. The surgical procedure did not influence either the morbidity or the mortality in patients irrespective of aetiology. Resection anastomosis was found to have a higher complication rate, but this was not statistically significant. Eggleston reported that the procedure done did not influence outcome. 16 Talwar and Sharma reported that mortality was least with early primary closure. Lag period has been known to influence both mortality and morbidity. Regression analysis showed that the mortality and morbidity increased with increasing lag period. Increasing lag period was associated with increased mortality in series by Archampong, Eggleston, Bose and Talwar. $18,16,3,24$

\section{SUMMARY AND CONCLUSIONS}

This study was conducted from July 2014 to December 2015. It includes fifty cases of peritonitis due to hollow viscus perforation admitted to Bowring and Lady Curzon Hospitals in that period. Aetiology, presentation, management and outcome of patients with perforations were studied with emphasis on the factors that influenced the prognosis. Typhoid fever is the most common cause of ileal perforation. Patients have a male preponderance and are usually in the second and third decades of their lives. Lag period has major impact on the patient recovery significantly influenced outcome. Shorter the log period, better the prognosis. Long lag period culminated in increased mortality and morbidity. The number of perforations directly had influence on the patient recovery. 
Single perforations had excellent prognosis, whereas multiple perforations resulted in higher morbidity and mortality.

\section{REFERENCES}

1. Agbakwuru EA, Adesunkanmi AR, Fadiora SO, et al. A review of typhoid perforation in rural African hospital. West Afr J Med 2003;22(1):22-5.

2. Ugwu BT, Yiltok SJ, Kidmas AT, et al. Typhoid intestinal perforation in north central Nigeria. West Afr J Med 2005;24(1):1-6.

3. Talwarr S, Sharmad A, Mittala IND, et al. Typhoid enteric perforation. Aust N Z J Surg 1997;67(6):351-3.

4. Parry EHO. Typhoid fever. In principles of medicine in Africa. Edited by: Parry EHO. Oxford: Oxford university press, 1984;2 ed:268-76.

5. Ajao 0G. Typhoid perforation: factors affecting mortality and morbidity. Int Surg 1982;67(4):317-9.

6. Carmeli Y, Raz R, Scharpiro JM. Typhoid fever in ethiopian immigrants to Israel and native- born Israelis: a comparative study. Clin Inf Dis 1993;16(2):213-5.

7. Chang YT, Lin JY. Typhoid colonic perforation in childhood: a ten year experience. World J Surg 2006;30(2):242-7.

8. Otegbayo JA, Daramola 00, Onyegbatulem HC, et al. Retrospective analysis of typhoid fever in a tropical tertiary health facility. Trop Gastroenterol 2002;23(1):912.

9. Edino ST, Yakubu AA, Mohammed AZ, et al. Prognostic factors in typhoid ileal perforation: a prospective study of 53 cases. J Natl Med Assoc 2007;99(9):1042-5.

10. Koume J, Kouadio L, Turquin HT. Typhoid ileal perforation: surgical experience of 64 cases. Acta Chir Belg 2004;104(4):445-7.

11. Naorani M, Sial I, Pain V. Typhoid perforation of small bowel: a study of 72 cases. J R Coll Surg Edinb 1997;42(4):274-6.
12. Foster EC, Lefor AT. General management of gastrointestinal fistulas: recognition, stabilization and correction of fluid and electrolyte imbalances. Surg Clin North Am 1996;76(5):1019-33.

13. Adesunkanmi AR, Ajao OG. The prognostic factors in typhoid ileal perforation: a prospective study of 50 patients. J R Coll Surg Edinb 1997;42(6):395-9.

14. Aziz M, Qadir A, Aziz M, et al. Prognostic factors in typhoid perforation. Journ Coll Physicians Surg Pak 2005;15(11):704-7.

15. Dixon JM, Lamusden AM, Piris J. Small bowel perforation. Journal of the Royal College of Surgeons of Edinburgh 1985;30(1):43-6.

16. Orringer RD, John A Coller, Veidenheimer MC. Spontaneous free perforation of the small intestine. Diseases of Colon Rectum 1983;26(5):323-6.

17. Keenan JP, Hadley GP. The surgical management of typhoid perforation in children. $\mathrm{Br} \mathrm{J}$ Surg 1984;71(12):928-9.

18. Archampong EQ. Typhoid ileal perforations: why such mortalities? Br J Surg 1976;63(4):317-21.

19. Kaul BK. Operative management of typhoid perforation in children. Int Surg 1975;60(8):407-10.

20. Vaidyanathan S. Surgical management of typhoid ileal perforation. Ind J Surg 1986;335-41.

21. Santillana M. Surgical complications of typhoid fever: enteric perforation. World J Surg 1991;15(2):170-5.

22. Donald E Meier, Obioha 0, Imediegwu, et al. Perforated typhoid enteritis: operative experience with 108 cases. Am J Surg 1989;157(4):423-7.

23. Mock CN, Amaral J, Visser LE. Improvement in survival from typhoid ileal perforation results of 221 operative cases. Ann Surg 1992;215(3):244-9.

24. Billing A, Frolich D, Schildberg FW. Prediction of outcome using manheim peritonitis index in 2003 patients peritonitis study group. Br J Surg 1994;81(2):209-13. 